\title{
Individual particle analysis of marine aerosols collected during the North-South transect cruise in the Pacific Ocean and its marginal seas
}

\author{
Momoka Yoshizue $^{1}(1) \cdot$ Yoko Iwamoto $^{2,3} \cdot$ Kouji Adachi $^{4} \cdot$ Shungo Kato $^{5} \cdot$ Siyi Sun $^{6,7} \cdot$ Kazuhiko Miura $^{2} \cdot$ \\ Mitsuo Uematsu ${ }^{6}$
}

Received: 6 December 2018 / Revised: 9 July 2019 / Accepted: 10 July 2019 / Published online: 16 August 2019

(c) The Author(s) 2019

\begin{abstract}
Sea-salt particles are major aerosol constituents in the marine boundary layer (MBL) and are chemically modified by acidic substances from anthropogenic, volcanic, and biogenic sources. When these acidic substances react with sea-salt particles, they can be easily scavenged from the MBL. This scavenging process influences the concentration of cloud condensation nuclei in the MBL. In this study, differences in chemical compositions of sea-salt particles collected over the Pacific Ocean and its marginal seas were investigated based on an individual particle analysis. The sources of the acidic substances that modified sea-salt particles were also estimated. Approximately $70 \%$ of the analyzed particles were fresh sea-salt particles. However, a sample collected near Guam was dominated by sulfates and was affected by polluted air masses that originated over the Asian continent. The aerosols collected around the Aleutian Islands included a large number of sulfates and modified sea-salt particles. Individual particle composition analyses indicate that these sea-salt particles were modified by methanesulfonic acid produced from marine biota and sulfuric acid from volcanic gas from the Kamchatka Peninsula. The gravitational deposition velocities of sulfates and modified sea-salt particles were calculated based on measured particle sizes. The results suggested that if acidic substances react with sea-salt particles, their lifetime in the atmosphere could be shortened due to dry deposition. Therefore, it is necessary to consider the scavenging effect of sea-salt particles for estimating the climate cooling effect by clouds over the ocean.
\end{abstract}

Keywords Marine atmospheric aerosol $\cdot$ Sea-salt $\cdot$ Sulfate $\cdot$ Volcanic gas $\cdot$ Dimethyl sulfide $\cdot$ Methanesulfonic acid

\section{Introduction}

Electronic supplementary material The online version of this article (https://doi.org/10.1007/s10872-019-00519-4) contains supplementary material, which is available to authorized users.

Momoka Yoshizue

1218707@ed.tus.ac.jp

1 Graduate School of Science, Tokyo University of Science, 1-3 Kagurazaka, Shinjuku, Tokyo 162-8601, Japan

2 Faculty of Science Division I, Tokyo University of Science, 1-3 Kagurazaka, Shinjuku, Tokyo 162-8601, Japan

3 Graduate School of Integrated Sciences for Life, Hiroshima University, 1-7-1, Kagamiyama, Higashi-Hiroshima, Hiroshima 739-8521, Japan

4 Meteorological Research Institute, 1-1 Nagamine, Tsukuba, Ibaraki 305-0052, Japan
Atmospheric aerosol particles play important roles in climate change because they can directly absorb and scatter solar radiation and form clouds by acting as cloud

5 Faculty of Urban Environmental Sciences, Tokyo Metropolitan University, 1-1 Minami-Osawa, Hachioji, Tokyo 192-0397, Japan

6 Atmosphere and Ocean Research Institute, The University of Tokyo, 5-1-5 Kashiwanoha, Kashiwa, Chiba 277-8564, Japan

7 JAPAN NUS Co., Ltd., 2-3-1 Minato Mirai, Nishi, Yokohama 220-6001, Japan 
condensation nuclei. For example, sea-salt particles scatter solar radiation and contribute to the cooling of the Earth. However, our scientific understanding is not sufficient to accurately evaluate the climate impact of the atmospheric aerosols (IPCC 2013).

Sea-salt particles originate from the ocean, which covers approximately $70 \%$ of the Earth's surface and thus has a particularly strong influence on global climate. Sea-salt particles are generated from a bubble bursting process on the sea surface. The chemical compositions of sea-salt particles are modified when they react with acidic substances such as sulfuric acid $\left(\mathrm{H}_{2} \mathrm{SO}_{4}\right)$, methanesulfonic acid (MSA; $\left.\mathrm{CH}_{3} \mathrm{SO}_{3} \mathrm{H}\right)$, and nitric acid $\left(\mathrm{HNO}_{3}\right)$. The reactions between sodium chloride $(\mathrm{NaCl})$, which is the main component of sea-salt particles, and the acidic substances are shown by the following chemical equations (Eqs. 1, 2, and 3).

$$
\begin{aligned}
& 2 \mathrm{NaCl}+\mathrm{H}_{2} \mathrm{SO}_{4} \rightarrow \mathrm{Na}_{2} \mathrm{SO}_{4}+2 \mathrm{HCl} \uparrow \\
& \mathrm{NaCl}+\mathrm{HNO}_{3} \rightarrow \mathrm{NaNO}_{3}+\mathrm{HCl} \uparrow \\
& \mathrm{NaCl}+\mathrm{CH}_{3} \mathrm{SO}_{3} \mathrm{H} \rightarrow \mathrm{CH}_{3} \mathrm{SO}_{3} \mathrm{Na}+\mathrm{HCl} \uparrow
\end{aligned}
$$

Major sources of $\mathrm{H}_{2} \mathrm{SO}_{4}$ are the combustion of fossil fuel, volcanic gas, and dimethyl sulfide (DMS) that originates from marine biota. $\mathrm{HNO}_{3}$ is mainly derived from the combustion of fossil fuel. MSA is produced by the oxidation of DMS.

$\mathrm{H}_{2} \mathrm{SO}_{4}$ is a precursor of sulfates that act as cloud condensation nuclei in the marine atmosphere (e.g., Ooki et al. 2003; Berresheim et al. 1993). Hara et al. (2005) showed that when $\mathrm{H}_{2} \mathrm{SO}_{4}$ reacts with sea-salt particles, the lifetime of sulfates in the atmosphere shortens because of scavenging by sea-salt particles along coastal Antarctica. Thus, the cooling effect by clouds is largely influenced by the abundance of sea-salt particles (Gong and Barrie 2003). To understand the climate impact of sea-salt particles, it is important to investigate the extent and cause of the modification of seasalt particles in different atmospheric environments.

Sea-salt particles modified by acidic substances have been reported in a number of studies. In urban coastal sites, some interactions between sea-salt particles and anthropogenic substances have been reported. For example, on the west coast of America, Adachi and Buseck (2015) reported that sea-salt particles were modified by $\mathrm{H}_{2} \mathrm{SO}_{4}$ or/and $\mathrm{HNO}_{3}$, and Laskin et al. (2012) additionally reported that the surroundings of sea-salt particles were modified by organic acid. Li et al. (2011) also observed the sea-salt particles similar to those reported in Laskin et al. (2012) in Macao. In the open ocean sites, Mouri et al. (1996) and Miura et al. (1991) reported the presence of sea-salt particles modified by $\mathrm{H}_{2} \mathrm{SO}_{4}$ and $\mathrm{HNO}_{3}$ near Japan and Indonesia. Mouri et al. (1999) reported the presence of sea-salt particles modified by acidic gases originating from marine biota over the Arctic
Ocean. Chi et al. (2015) also reported the presence of seasalt particles partially or completely modified by $\mathrm{HNO}_{3}$ as well as by $\mathrm{H}_{2} \mathrm{SO}_{4}$ over the Arctic Ocean. Hara et al. (2005) showed that sea-salt particles were modified not only by $\mathrm{H}_{2} \mathrm{SO}_{4}$, but also by MSA in coastal Antarctica. These studies showed that the modification processes of sea-salt particles occur in various regions and causes.

In this study, we perform individual particle analyses focused on sea-salt particles collected across the globe from the Arctic Ocean to the South Pacific to understand the extent of sea-salt compositional changes over the ocean using a transmission electron microscope equipped with an energy dispersive X-ray spectrometer (TEM-EDX). In addition, the sources of the acidic substances that modify the sea-salt particles are also discussed.

\section{Methods}

\subsection{Observation}

Aerosol samples were collected onboard the R/V Hakuho Maru during the KH-13-7 cruise and the KH-14-3 Leg2 cruise in the Pacific Ocean and its marginal seas using a 3 -stage impactor. Sampling was performed only when there was no contamination from the vessel itself, based on the particle number concentration and the wind direction, which were measured continuously on the vessel. The cruise tracks and the sampling points are shown in Fig. 1. In this study, 8 samples were collected among the various ocean regions: No. 1, the Arctic Ocean; No. 2, the Bering Sea; No. 3, around the Aleutian Islands; No. $4,35^{\circ} \mathrm{N}$ in the trade wind belt; No. 5, around the equator; No. 6, the South Pacific; No. 7. around New Zealand; and No. 8, around Guam (Fig. 1). Five-days backward trajectories starting from $500 \mathrm{~m}$ above sea level (a. s. 1.) at the sampling points were calculated using the NOAA Hysplit Model (http://www.ready.noaa. gov/HYSPLIT.php) (Rolph et al. 2017; Stein et al. 2015) to estimate the origins of the sampled air masses (Fig. 1). The $50 \%$ cut-off aerodynamic diameters of the impactor were 4 , 0.5 and $0.25 \mu \mathrm{m}$ with a flow rate of $1.0 \mathrm{~L} \cdot \mathrm{min}^{-1}$. The sampling time varied from 10 to 20 min during the KH-13-7 cruise and from 1 to 5 min during the KH-14-3 Leg2 cruise, depending on the particle number concentration. A carboncoated nitrocellulose (collodion) film supported on a $\mathrm{Cu}$ grid was used for the collection substrates.

During both cruises, particle number concentrations were continuously measured using an optical particle counter (OPC; KC-01D, RION) with 5 channels in diameters greater than $0.3,0.5,1,2,5 \mu \mathrm{m}$. The OPC was installed in an observation box mounted in front of the upper deck and the sampled air was introduced to the box from an inlet on its ceiling. During the KH-13-7 cruise, the sampled air was dried 


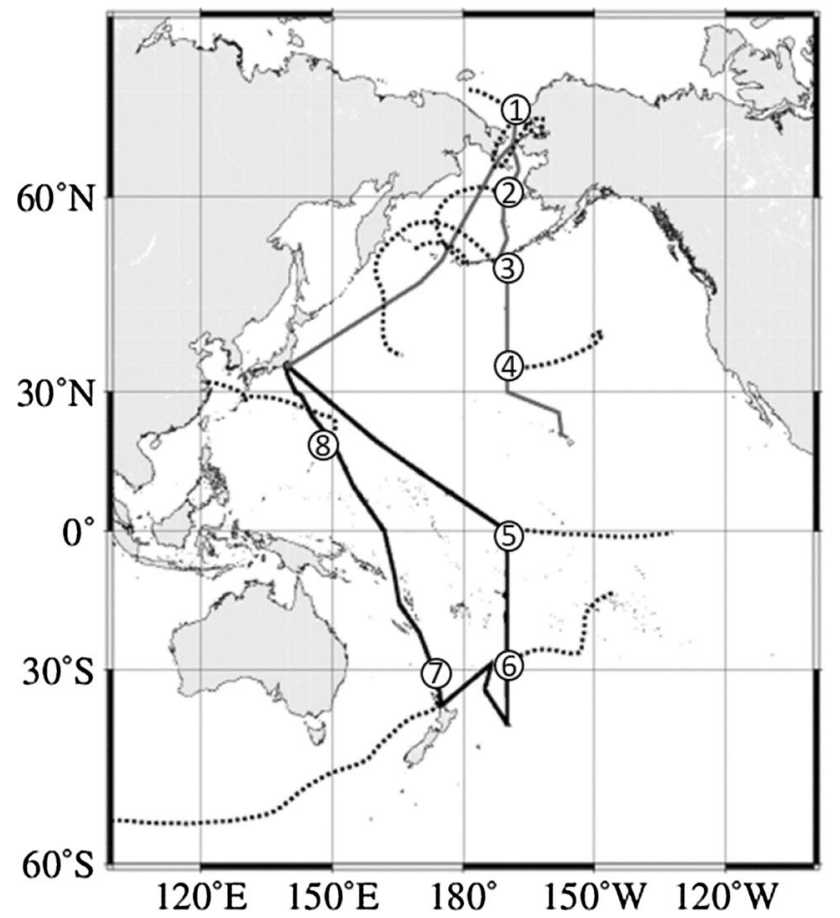

Fig. 1 Cruise tracks of the KH-13-7 cruise (black line) and the KH-14-3 Leg2 cruise (gray line). Circled numbers indicate the sampling points (1): No. 1 the Arctic Ocean, (2): No. 2 the Bering Sea, (3): No. 3 around the Aleutian Islands, (4): No. $435^{\circ} \mathrm{N}$ in the trade wind belt, (5): No. 5 around the equator, (6: No. 6 the South Pacific, (7): No. 7 around New Zealand, (8: No. 8 around Guam). The dotted lines show five-days backward trajectories starting from $500 \mathrm{~m}$ a. s. 1 . at the sampling points

prior to sampling to a relative humidity less than $30 \%$ using a diffusion dryer. The radon concentration was measured using two radon counters (the KH-13-7 cruise: ES-74230, JREC CO., Ltd.; the KH-14-3 Leg2 cruise: ES-7267, JREC CO., Ltd.). Radon is chemically inactive and decreases through radioactive decay. Since radon mainly originates from soil, radon in the atmosphere over the ocean can be used as a tracer of air masses from continents. Furthermore, a high-volume air sampler (AS-9, KIMOTO ELECTRIC CO., LTD.) collected aerosol particles on filters every $24 \mathrm{~h}$. To minimize contamination from the vessel, the samples were collected only when the relative wind directions to the bow were from $-90^{\circ}$ to $+90^{\circ}$ and the relative wind speed was more than $1 \mathrm{~m} \mathrm{~s}^{-1}$. The filter samples were analyzed using ion chromatography to measure the concentration of MSA and water-soluble ion components in the laboratory. Air samples were also collected in canisters to measure atmospheric DMS concentrations using GC-FID (GC6890, Agilent Co. Ltd.) in the laboratory.

\subsection{EDX analysis}

Elemental compositions of individual particles were determined using an energy dispersive X-ray spectrometer (EDX; Oxford X-MAX-80, Oxford Instruments) equipped with a transmission electron microscope (TEM; JEM-1400, JEOL). The circle equivalent diameters were measured from the particle areas obtained from the TEM image. We determined the relative masses of $\mathrm{C}, \mathrm{N}, \mathrm{O}, \mathrm{Na}, \mathrm{Mg}, \mathrm{Al}, \mathrm{Si}, \mathrm{P}, \mathrm{S}, \mathrm{Cl}, \mathrm{K}$, $\mathrm{Ca}, \mathrm{Ti}, \mathrm{Mn}, \mathrm{Fe}$ and $\mathrm{Zn}$ for individual particles using software in the EDX (INCA, Oxford Instruments). If the count rate of characteristic X-rays is less than 12.5 counts s ${ }^{-1}$ or the relative mass ratio of a certain element exceeds $100 \%$, the data are excluded from the discussion due to high uncertainty (approximately $7 \%$ of all data). To verify the quantitative analysis, laboratory-generated standard $\mathrm{NaCl}$ particles using $0.1 \% \mathrm{NaCl}$ solution made with $\mathrm{NaCl}$ of $99.5 \%$ purity (KANTO CHEMICAL CO., INC.) were measured using the EDX. Based on the result of the standard particles, particles with circle equivalent diameters larger than $0.3 \mu \mathrm{m}$ were used for the following analysis (Text S1).

\subsection{Definition of sea-salt particles}

The composition of fresh sea-salt particles may be the same as that of sea water, and the relative mass ratio of $\mathrm{Na}$ within the main six elements $(\mathrm{Na}, \mathrm{Cl}, \mathrm{S}, \mathrm{Mg}, \mathrm{K}, \mathrm{Ca})$ of sea water is approximately $30 \%$. However, the relative Na mass ratio commonly decreases when sea-salt particles completely deplete $\mathrm{Cl}$ and attach excessive $\mathrm{S}$ on their surfaces. Thus, in this study, according to Miura (2000), sea-salt particles are defined as those that contain more than $15 \% \mathrm{Na}$ in the total mass.

\section{Results}

\subsection{General descriptions of the sampling periods}

During both cruises, we monitored continuously meteorological parameters and concentrations of radon and aerosol particles. Both the radon concentration and particle number concentration were the highest around Guam (No. 8) (Table 1). However, the radon concentration was low over the central part of the Pacific (No. 4-6). The DMS concentrations were relatively high over the Northern Hemisphere (No. 1-4), especially over the Arctic Ocean (No. 1) and around the Aleutian Islands (No. 3), but the concentration was below the detection limit around Guam (No. 8). The MSA concentrations were high over the Arctic Ocean (No. 1), the South Pacific (No. 6) and around Guam (No. 8), but they were below the detection limit over the central part of the Pacific (No. 4, 5). The concentration of $\mathrm{SO}_{4}^{2-}$ was 


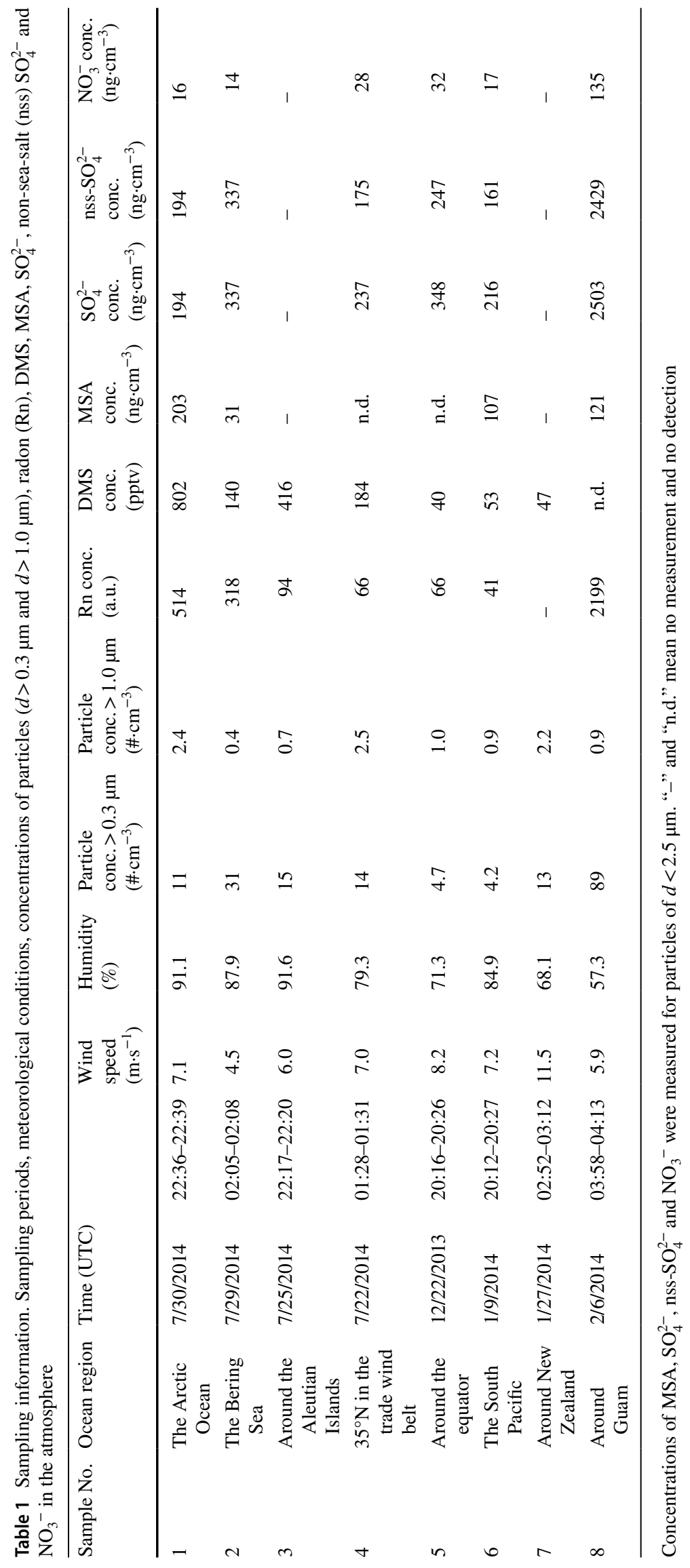


the highest around Guam (No. 8) and was the lowest over the Arctic Ocean (No. 1). The concentration of non-seasalt $\mathrm{SO}_{4}^{2-}$ (nss- $\mathrm{SO}_{4}^{2-}$ ) was the highest around Guam (No. 8). All $\mathrm{SO}_{4}^{2-}$ was nss-SO ${ }_{4}^{2-}$ over the Arctic Ocean (No. 1) and the Bering Sea (No. 2). The concentration of $\mathrm{NO}_{3}^{-}$was the highest around Guam (No.8) and was relatively low over the other ocean regions.

\subsection{Classification of particles}

In this study, elemental compositions, shapes and sizes of the particles collected in the middle stage $(0.5 \mu \mathrm{m}$ of $50 \%$ cut-off diameter) were analyzed. The circle equivalent diameters of the analyzed particles measured using TEM agree with the cut-off sizes (Text S2).

The analyzed particles were classified into the following categories (Text S3): "C-rich", "Sea-salt", "Modified sea-salt", "Sulfate", "Potassium salt", "Sea-salt + Mineral", "Modified sea-salt + Mineral", "Sulfate + Mineral", "Potassium salt + Mineral", "Mineral" and "Others". Figure 2 shows the number fractions of the particle classification for each sample. Sea-salt particles accounted for more than $80 \%$ and modified sea-salt particles accounted for $0-5 \%$ in the samples collected over the Arctic Ocean (No. 1), $35^{\circ} \mathrm{N}$ in the trade wind belt (No. 4), around the equator (No. 5), over the South Pacific (No. 6) and around New Zealand (No. 7). The samples collected over the Bering Sea (No. 2) and around the Aleutian Islands (No. 3) contained more sulfates and modified sea-salt particles than the other samples. In addition, the sample collected around Guam (No.8) contained more than $85 \%$ sulfates and approximately $12 \%$ sulfate + mineral particles. Recently, several studies pointed out that Fe-bearing particles have large impact on the global carbon cycle by effecting ocean biogeochemistry through the deposition of soluble Fe to the ocean (e.g., Furutani et al. 2011; Matsui et al. 2018). For example, $\mathrm{Li}$ et al. (2017) reported that $\mathrm{Fe}$ particles collected over the East China Sea were embedded in sulfates emitted from anthropogenic combustion and had spherical shapes and sometimes aggregated. However, Fecontaining particles accounted for only approximately $0.3 \%$ in our samples.

\section{3 $\mathrm{Cl} / \mathrm{Na}$ ratio}

To investigate the extent of modification of sea-salt particles, we calculated the $\mathrm{Cl} / \mathrm{Na}$ mass ratio $(\mathrm{Cl} / \mathrm{Na}$ ratio) of sea-salt particles such as "Sea-salt", "Modified sea-salt", "Sea-salt + Mineral" and "Modified sea-salt + Mineral" (Fig. 3). The median $\mathrm{Cl} / \mathrm{Na}$ ratios of samples No. 2 and 4-7 agree with that of standard particles or theoretical $\mathrm{NaCl}$, but those of collected over the Arctic Ocean (No. 1) and around

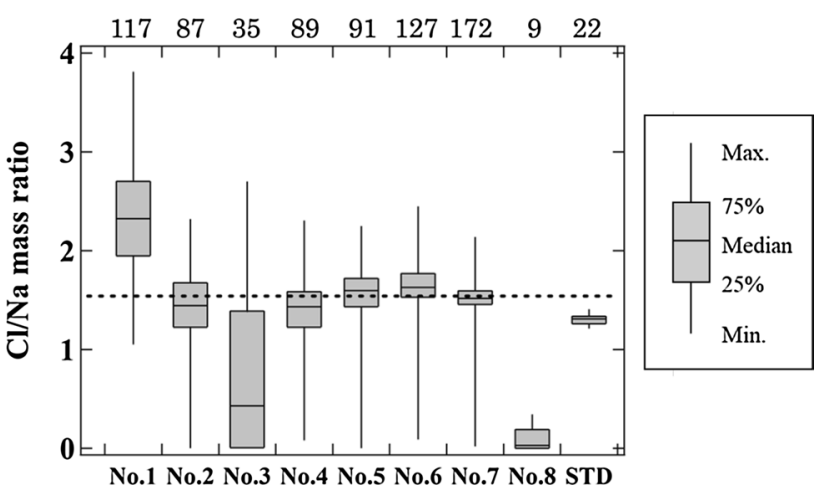

Fig. 3 Box plot of $\mathrm{Cl} / \mathrm{Na}$ mass ratios for each ocean region and standard particles. Horizonal axis indicates sample numbers and STD which means standard particles. The numbers above the graph indicate the total number of "Sea-salt", "Sea-salt + Mineral", "Modified sea-salt" and "Modified sea-salt + Mineral" particles. The dashed line shows the ratio of pure $\mathrm{NaCl}$ (1.54)
Fig. 2 Number fractions of particles for each ocean region. Horizonal axis indicates sample numbers. The values above the graph indicate the number of analyzed particles

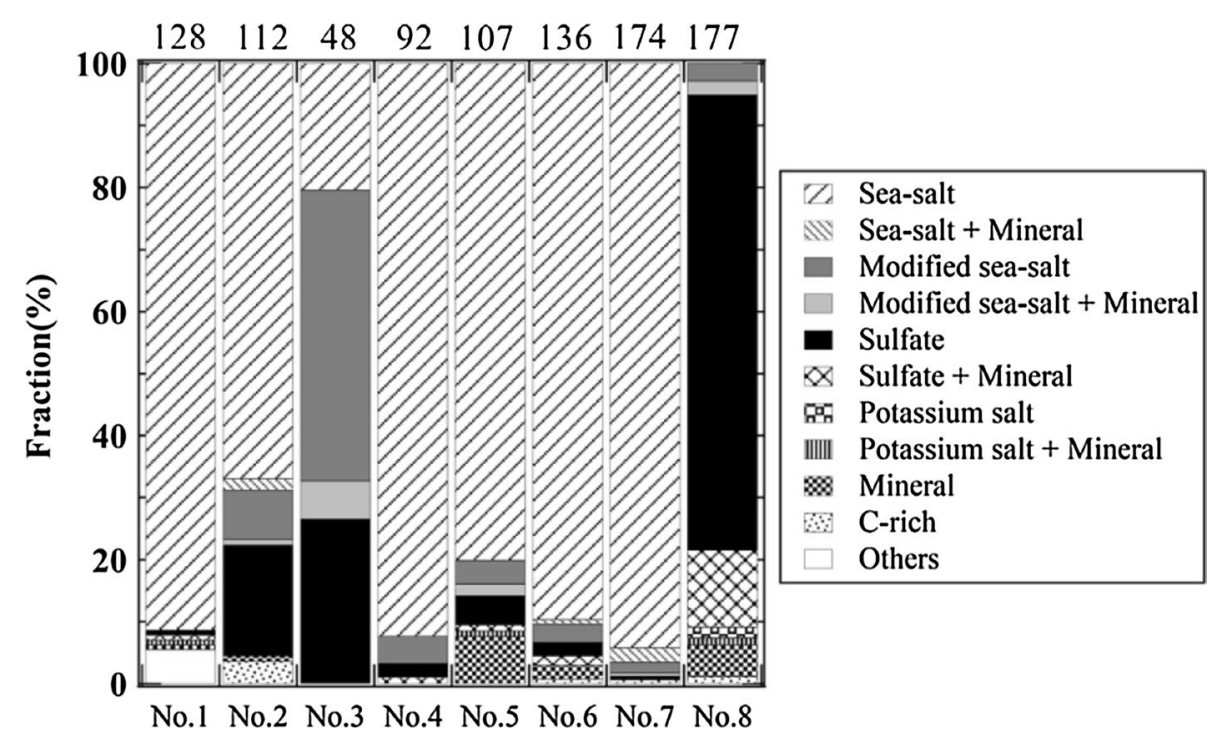


Guam (No. 8) were, respectively, much larger and smaller than standard particles. Possible reasons for the anomalous $\mathrm{Cl} / \mathrm{Na}$ ratios are discussed later. Specifically, most of the sea-salt particles collected around Guam (No. 8) were completely depleted $\mathrm{Cl}$. For the sample collected around the Aleutian Islands (No. 3), the $\mathrm{Cl} / \mathrm{Na}$ ratio varied widely and the modification of sea-salt particles was diverse, possibly due to the size variation of the analyzed particles (Text S2).

The relationship between $\mathrm{Cl} / \mathrm{Na}$ ratios and circle equivalent diameters in Fig. 4 shows that $78 \%$ of the analyzed particles roughly agree with the $\mathrm{Cl} / \mathrm{Na}$ ratio of $\mathrm{NaCl}(1.54 \pm 0.5)$, although there are some exceptions. For example, approximately $8 \%$ of particles $<1.0 \mu \mathrm{m}$ have small $\mathrm{Cl} / \mathrm{Na}$ ratios. This trend has been reported in previous studies (Mouri and Okada 1993), which explained that (1) the smaller particles have longer lifetimes in the atmosphere and are more likely to react with acidic substances, and (2) smaller particles have larger surface-to-volume ratios. Additionally, in the sample collected around the Aleutian Islands (No. 3), some particles $>1.0 \mu \mathrm{m}$ had small $\mathrm{Cl} / \mathrm{Na}$ ratios. The reason for this is discussed in Sect. 4.2.

\subsection{Sea-salt particles collected over each ocean region}

To discuss the species of acidic substances that modified the sea-salt particles over each ocean region, variations in the relative mass ratio of $\mathrm{Na}, \mathrm{S}$ and $\mathrm{Cl}$ in individual seasalt particles are shown in Fig. 5 by reference to Hara et al. (2005). In the ternary diagrams, dashed lines and dotted lines show the stoichiometric change in chemical composition from $\mathrm{NaCl}$ to $\mathrm{Na}_{2} \mathrm{SO}_{4}$ and $\mathrm{CH}_{3} \mathrm{SO}_{3} \mathrm{Na}$. Therefore, plots

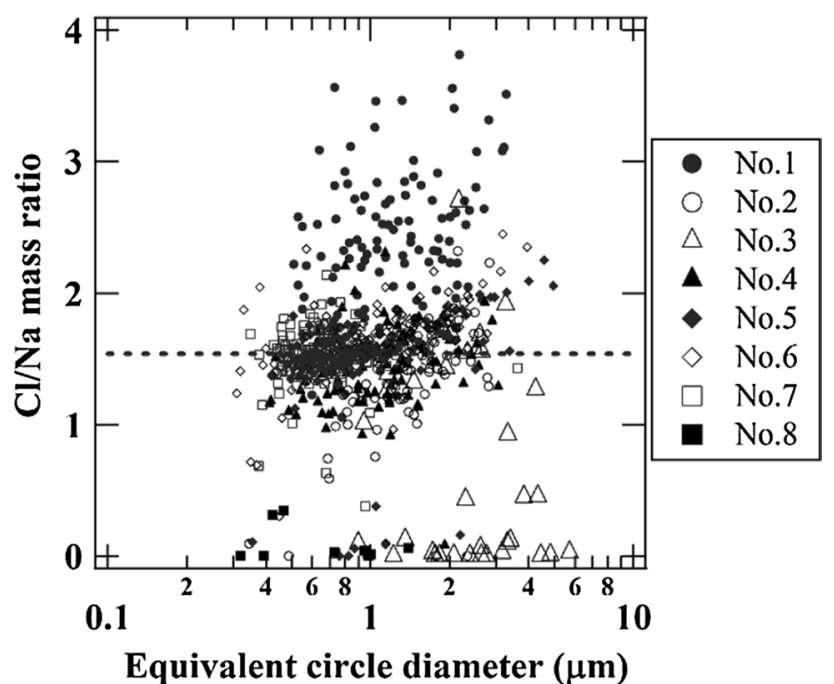

Fig. $4 \mathrm{Cl} / \mathrm{Na}$ mass ratios for individual sea-salt particles versus equivalent circle diameters. The dashed line shows $\mathrm{Cl} / \mathrm{Na}$ mass ratio of pure $\mathrm{NaCl}$ (1.54) around dashed and dotted lines indicate the sea-salt particles modified by $\mathrm{H}_{2} \mathrm{SO}_{4}$ and MSA, respectively. When sea-salt particles are modified by other acidic substances such as $\mathrm{HNO}_{3}$ and organic acids, they are plotted above dashed lines and it cannot be determined which acid substance modified sea-salt particles. Even if sea-salt particles do not react with MSA, those containing minerals such as $\mathrm{Ca}$ and $\mathrm{Mg}$ are plotted on dotted lines due to their relatively low proportion of $\mathrm{Na}$, therefore, they are separately plotted. Sulfur dioxide is sometime taken into sea-salt particles in aqueous-phase to form $\mathrm{S}(\mathrm{IV})$ such as $\mathrm{NaHSO}_{3}$, however, $\mathrm{S}(\mathrm{IV})$ is quickly oxidized to $\mathrm{S}(\mathrm{VI})$ such as $\mathrm{Na}_{2} \mathrm{SO}_{4}$ (Seinfeld and Pandis 2016). Therefore, the presence of $\mathrm{NaHSO}_{3}$ is not considered.

There are few sea-salt particles modified by $\mathrm{HNO}_{3}$ or organic acids over all ocean regions. The sample collected over the Arctic Ocean (No. 1) did not contain modified seasalt particles, i.e., they were fresh, $\mathrm{Cl}$-rich sea-salt particles. Only a few sea-salt particles were modified by $\mathrm{H}_{2} \mathrm{SO}_{4}$ and MSA in samples collected over the Bering Sea (No. 2), $35^{\circ} \mathrm{N}$ in the trade wind belt (No. 4), around the equator (No. 5), the South Pacific (No. 6) and around New Zealand (No. 7). In the sample collected around the Aleutian Islands (No. 3), some sea-salt particles were modified by MSA and some sea-salt particles were completely depleted $\mathrm{Cl}$ and contained excessive S. In the sample collected around Guam (No. 8), almost all sea-salt particles were completely depleted $\mathrm{Cl}$. In this study, we further focused on samples that had different extents of modification of sea-salt particles collected over the Arctic Ocean (No. 1), around the Aleutian Islands (No. 3) and around Guam (No. 8).

\section{Discussion}

\subsection{Arctic ocean}

The sea-salt particles collected over the Arctic Ocean (sample No. 1) were less modified and many particles had higher $\mathrm{Cl} / \mathrm{Na}$ ratios than that of sea water (Fig. 3). The high $\mathrm{Cl} /$ $\mathrm{Na}$ ratio could be caused by other chloride salts containing $\mathrm{Mg}, \mathrm{Ca}$ or $\mathrm{K}$, all of which are present in sea water. Hara et al. (2005) reported that sea-salt particles produced by fractionation in sea ice contain more $\mathrm{Mg}, \mathrm{Ca}$ and $\mathrm{K}$ than sea water. The ternary diagrams in Fig. 6 suggest that the sea-salt particles include $\mathrm{Mg}, \mathrm{Ca}$ and $\mathrm{K}$, and specifically that they contain more $\mathrm{Mg}$ than sea water, consistent with results of Hara et al. (2013). The results indicate that the presence of $\mathrm{Mg}, \mathrm{Ca}$ and $\mathrm{K}$ chloride particles increased the $\mathrm{Cl} / \mathrm{Na}$ ratio in the Arctic Ocean.

Although the concentrations of atmospheric DMS and MSA were high in this sample, there were few sea-salt particles that were modified by MSA and $\mathrm{H}_{2} \mathrm{SO}_{4}$. A possible reason is that these particles were freshly emitted by a strong 

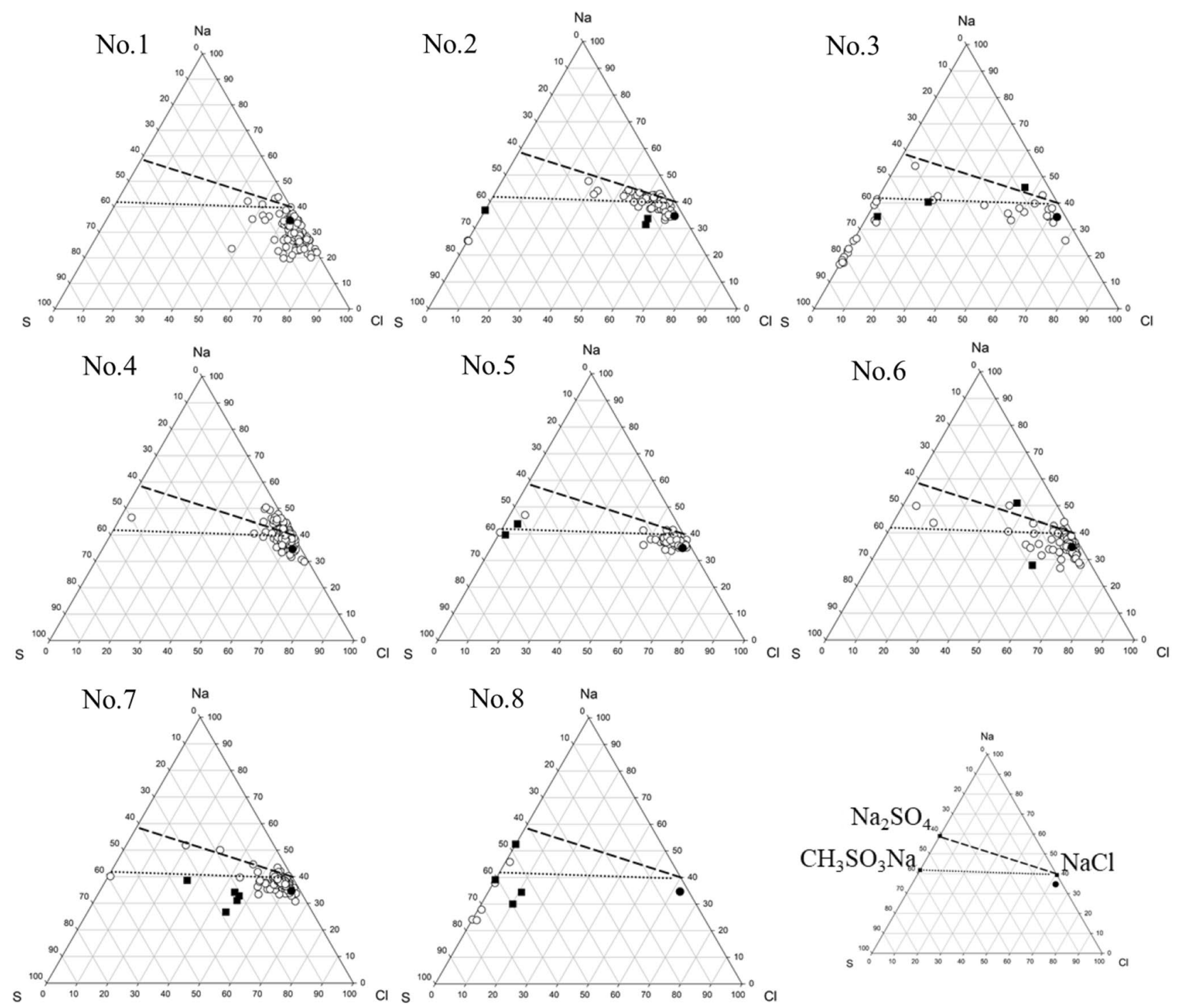

Fig. 5 The relative mass ratios of $\mathrm{Na}-\mathrm{S}-\mathrm{Cl}$ of individual sea-salt particles. Black circles show the composition of sea water. Open circles show "Sea-salt" or "Modified sea-salt" and black squares show "Seasalt + Mineral" or "Modified sea-salt + Mineral". Dashed and dot- ted lines show the stoichiometric lines of $\mathrm{NaCl}-\mathrm{Na}_{2} \mathrm{SO}_{4}$ and $\mathrm{NaCl}-$ $\mathrm{CH}_{3} \mathrm{SO}_{3} \mathrm{Na}$, respectively. Plots on the dashed lines and dotted lines indicate modification by $\mathrm{H}_{2} \mathrm{SO}_{4}$ and MSA, respectively. Plots above the dashed lines indicate modification by other acidic substances wind. The wind speed at the sampling site was $7.1 \mathrm{~m} \mathrm{~s}^{-1}$, which is higher than that in other ocean regions (Table 1). When the wind speed is high, the generation of sea-salt particles from the ocean surface increases. As a result, there may be many fresh sea-salt particles that had little time to react with acidic substances over the observed area in the Arctic Ocean, resulting in many unreacted sea-salt particles.

\subsection{Around the Aleutian Islands}

Around the Aleutian Islands (sample No. 3), the $\mathrm{Cl} / \mathrm{Na}$ ratio varied widely, and the extent of modification of sea-salt particles was variable (Fig. 3). The plots on the dotted line in
Fig. 5 No. 3 indicated that approximately half of sea-salt particles were modified by MSA. On the other hand, the remaining sea-salt particles were completely depleted $\mathrm{Cl}$ and contained excessive $\mathrm{S}$, suggesting that acidic substances other than MSA could contribute the modification of seasalt particles. Judging from its backward trajectory (Fig. 1), the influences of anthropogenic sources on the sample were small. However, according to VOLCANO DISCOVERY (http://www.volcanodiscovery.com; accessed on November 1, 2017), the Zhupanovsky volcano (altitude: $2958 \mathrm{~m}$ ) on the Kamchatka peninsula erupted from July 16 to 21, 2014, and the volcanic smoke reached $7 \mathrm{~km}$ a. s. 1. on July 16 . The forward trajectories starting from the Zhupanovsky volcano 


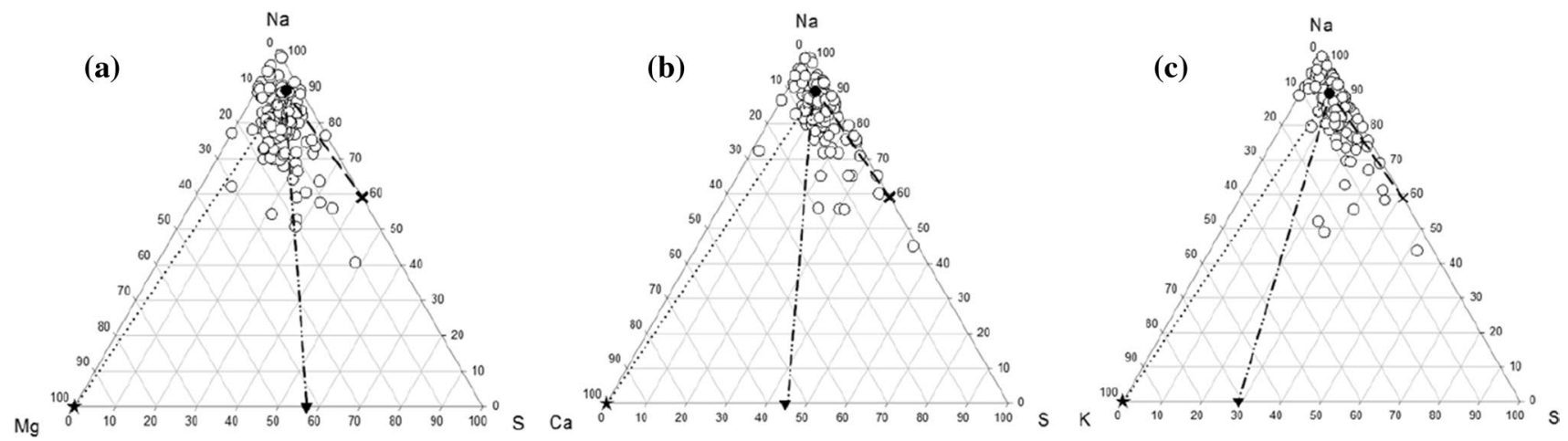

Fig. 6 The relative mass ratios of a $\mathrm{Na}-\mathrm{Mg}-\mathrm{S}, \mathbf{b} \mathrm{Na}-\mathrm{Ca}-\mathrm{S}$, and $\mathbf{c}$ $\mathrm{Na}-\mathrm{K}-\mathrm{S}$ of individual sea-salt particles. Black circles and crosses show the compositions of sea water and $\mathrm{Na}_{2} \mathrm{SO}_{4}$, respectively. Dashed lines show the stoichiometric line of sea water- $\mathrm{Na}_{2} \mathrm{SO}_{4}$. Stars and inverted triangles show $\mathrm{MgCl}_{2}$ and $\mathrm{MgSO}_{4}$ in (a), $\mathrm{CaCl}_{2}$ and $\mathrm{CaSO}_{4}$

(altitude: $3000 \mathrm{~m}$ ) were calculated during the eruption using the NOAA Hysplit model (Fig. 7a). The forward trajectories starting at 15:00 and 16:00 on July 20 reached the sampling point on the afternoon of July 25 when the TEM sample was collected. Therefore, in addition to biogenic sulfur, $\mathrm{H}_{2} \mathrm{SO}_{4}$ from the volcano on the Kamchatka Peninsula possibly contributed to the modification of sea-salt particles.

Giant sulfates whose diameters were more than $2 \mu \mathrm{m}$ were observed in this sample (Fig. 7b, c). Mouri et al. (1995) and Tomimatsu et al. (2012) observed similar giant sulfates in the marine atmosphere. Tomimatsu et al. (2012) showed that when a volcanic smoke reaches the free troposphere, giant sulfates can be generated by gas-to-particle conversion and coagulation during sedimentation. In this study, the backward trajectory passed through the Kamchatka Peninsula 3 days before reaching the sampling point (Fig. 1), and then its air masses came down between the marine boundary layer and the free troposphere (approximately $1500 \mathrm{~m} \mathrm{a.} \mathrm{s.} \mathrm{1.)}$ (Fig. 7d). This trajectory suggests that the giant sulfates were generated during sedimentation. Moreover, its air masses experienced high humidity states $24 \mathrm{~h}$ prior to reaching the sampling point (Fig. 7d), which is a condition that possibly promotes sulfate growth (LeGrande et al. 2016).

\subsection{Around Guam}

The sea-salt particles collected around Guam (sample No. 8) had very low $\mathrm{Cl} / \mathrm{Na}$ ratios and contained excessive $\mathrm{S}$ (Figs. 3, 5). In addition, sulfates accounted for more than $85 \%$ in this sample (Fig. 2). The concentrations of radon, nss- $\mathrm{SO}_{4}^{2-}$ and $\mathrm{NO}_{3}^{-}$were one order higher than those of other ocean regions (Table 1). Its backward trajectory indicated the long-range transport of air masses form the Asian continent without passing near Guam island (Fig. 1). These results indicate that in (b) and $\mathrm{KCl}$ and $\mathrm{K}_{2} \mathrm{SO}_{4}$ in (c). Dotted lines and two-dot chain lines show the stoichiometric lines of sea water- $\mathrm{MgCl}_{2}$ and sea water$\mathrm{MgSO}_{4}$ in (a), sea water-CaCl 2 and sea water-CaSO${ }_{4}$ in (b) and sea water- $\mathrm{KCl}$ and sea water- $\mathrm{K}_{2} \mathrm{SO}_{4}$ in (c)

sea-salt particles were modified by anthropogenic $\mathrm{H}_{2} \mathrm{SO}_{4}$ in the polluted air masses derived from the Asian continent.

\subsection{Deposition velocities of modified sea-salt particles and sulfates}

There are few studies to calculate the deposition velocities of sulfates reacting sea-salt particles quantitatively, therefore we actually calculated them in this study. Figure 8 shows the gravitational deposition velocities $V_{x}$ were calculated using their geometric mean particle sizes and densities, according to Kasten (1968). A sulfate and a modified sea-salt particle are assumed to be $\mathrm{H}_{2} \mathrm{SO}_{4} \cdot \mathrm{H}_{2} \mathrm{O}$ and $\mathrm{Na}_{2} \mathrm{SO}_{4}$, respectively, and Stokes' formula (Eq. 4) was used for the calculation.

$V_{x}=\frac{2}{9} \frac{\left(\rho_{\mathrm{p}}-\rho_{\mathrm{a}}\right)}{\mu}\left(\frac{d}{2}\right)^{2} g$

where $\rho_{\mathrm{p}}$ is the density of a particle $\left(\rho_{\mathrm{H}_{2} \mathrm{SO}_{4} \cdot \mathrm{H}_{2} \mathrm{O}}=1.79 \mathrm{~g} \mathrm{~cm}^{-3}\right.$, $\left.\rho_{\mathrm{Na}_{2} \mathrm{SO}_{4}}=2.66 \mathrm{~g} \mathrm{~cm}^{-3}\right), \rho_{\mathrm{a}}$ is the density of air, $\mu$ is the viscosity of the air (U.S. Standard Atmosphere 1976) and $d$ is the particle diameter. The mean values and the standard deviation of gravitational deposition velocities of sulfates and modified sea-salt particles were $0.16 \pm 0.13 \mathrm{~m} \mathrm{~h}^{-1}$ and $0.81 \pm 1.1 \mathrm{~m} \mathrm{~h}^{-1}$, respectively. When $\mathrm{H}_{2} \mathrm{SO}_{4}$ reacts with a sea-salt particle, the gravitational deposition velocity can be approximately five times greater than when $\mathrm{H}_{2} \mathrm{SO}_{4}$ becomes a sulfate particle. This result suggests that when the acidic substances react with sea-salt particles, their lifetime in the atmosphere could shorten in terms of dry deposition. 
Fig. 7 a Five-days forward trajectories starting from the Zhupanovsky volcano (altitude: $3000 \mathrm{~m}$ ). A cross shows the sampling point. The start times of trajectories were 16:00 and 17:00 on July 20, 2014. b Particle classification based on their sizes. c TEM image of the sample. The black, a black-dashed and white arrows indicate "Sea-salt", "Modified sea-salt" and "Sulfate", respectively. d Altitude and relative humidity of air masses obtained from the three-days backward trajectory
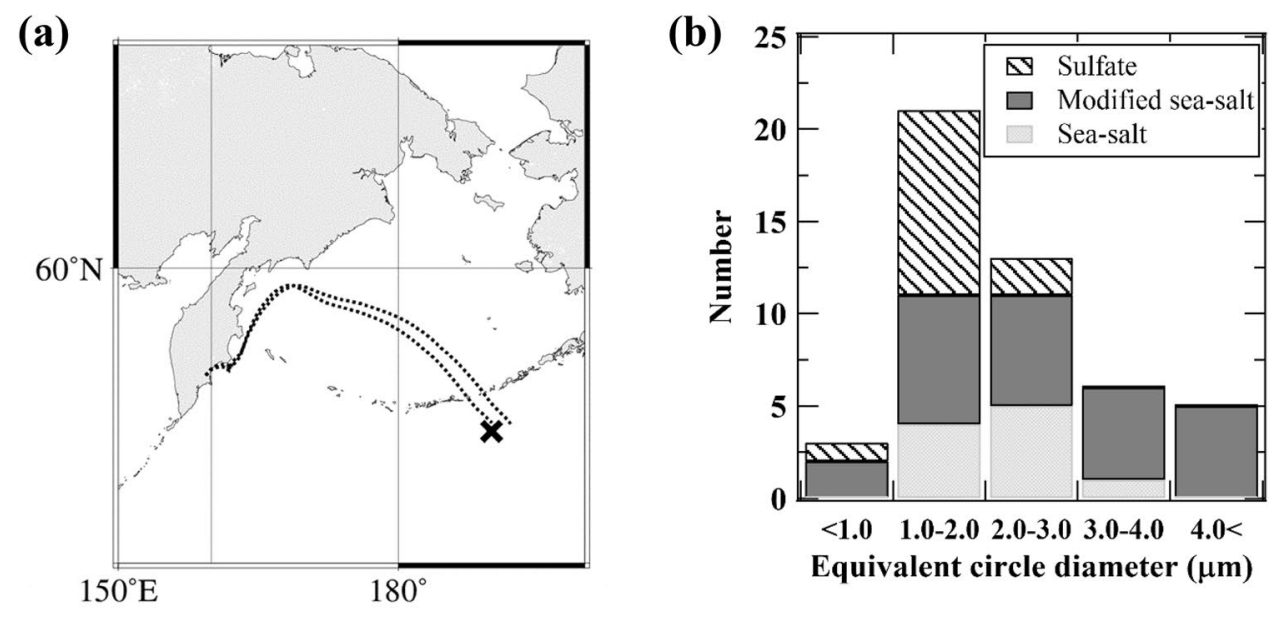
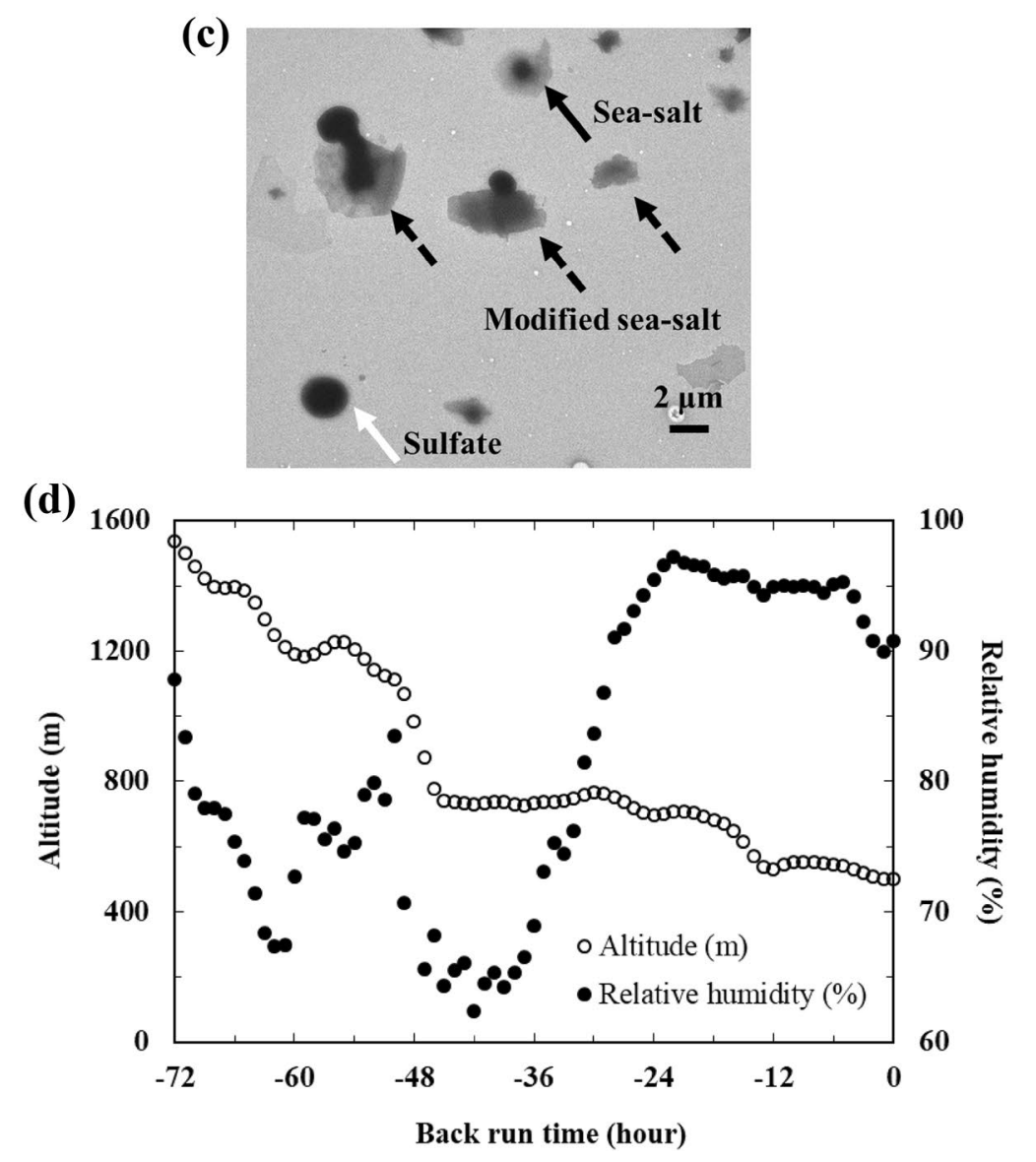

\section{Conclusion}

Individual particle analyses using TEM-EDX were performed on aerosol particles collected over a wide area of the Pacific Ocean and its marginal seas. The results in this study are summarized as follows.

(1) Fresh sea-salt particles accounted for approximately $80 \%$ of the constituents in the samples collected over most observed ocean regions.
(2) The sea-salt particles collected over the Arctic Ocean had greater $\mathrm{Cl} / \mathrm{Na}$ mass ratios than the other samples. These sea-salt particles contained many $\mathrm{Ca}, \mathrm{Mg}$, and $\mathrm{K}$ chloride particles.

(3) The sample collected around the Aleutian Islands contained high sulfate and modified sea-salt particle fractions compared to the other samples. The sea-salt particles are possibly modified by MSA that formed through the oxidation of DMS that originated from marine biota 


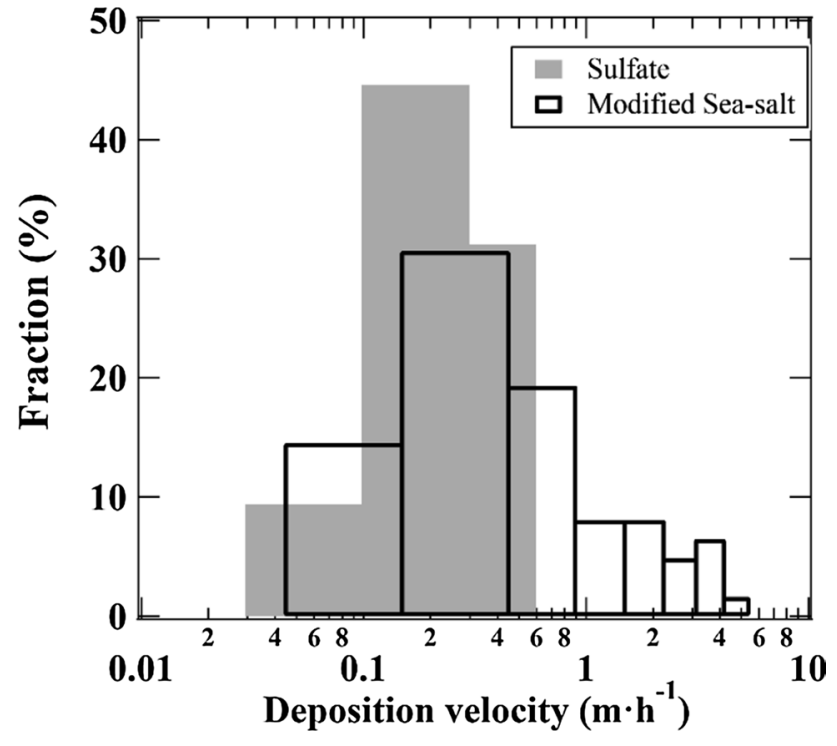

Fig. 8 Deposition velocities of $\mathrm{H}_{2} \mathrm{SO}_{4} \bullet \mathrm{H}_{2} \mathrm{O}$ and $\mathrm{Na}_{2} \mathrm{SO}_{4}$. The histograms show the particle size distributions of sulfates (gray column; "Sulfate" and "Sulfate + Mineral") and modified sea-salt particles (black column; "Modified sea-salt" and "Modified seasalt + Mineral")

and $\mathrm{H}_{2} \mathrm{SO}_{4}$ that originated from a volcanic plume that emanated from the Kamchatka Peninsula.

(4) Sulfates accounted for $85 \%$ of the sample collected around Guam. Most sea-salt particles were completely depleted $\mathrm{Cl}$ and contained excessive $\mathrm{S}$ due to the influence of polluted air masses derived from the Asian continent.

(5) Approximately $30 \%$ of modified sea-salt particles had diameters larger than $2.0 \mu \mathrm{m}$, whereas most sulfates had diameters less than $2.0 \mu \mathrm{m}$. Their gravitational deposition velocities suggested that if the acidic substances react with sea-salt particles, their lifetime in the atmosphere shortens due to dry deposition, implying the importance of the scavenging effect of sea-salt particles for Earth's radiation budget.

We found that sea-salt particles and sulfate dominated the aerosol particles over the open ocean. These particles also interact with each other, forming modified sea-salt particles at the individual particle scale. The sources of sulfur varied widely, including anthropogenic, volcanic, and biological activities, depending on location and air mass history. The sizes of particles reflect their transport history, and eventually affect their atmospheric lifetime. These results show that, although the marine aerosol particles were collected far from continents and anthropogenic sources, they still change their compositions at the individual scale with age. Therefore, if it was assumed that they were just sodium chloride particles, their influences on the climate would not be accurately evaluated; the consideration of their modification processes is important for marine aerosol particles.

Acknowledgements This study was supported by funds from the Ministry of Education, Culture, Sports, Science and Technology, Japan; Grant-Aid for Scientific Research on Innovative Areas "New Ocean Paradigm on Its Biogeochemistry, Ecosystem and Sustainable Use (NEOPS)" under Grant No. 25121504. This study was also supported by the Research Fund of Tokyo University of Science, Japan. We are grateful to the captains and crews of the R/V Hakuho Maru of KH-13-7 and KH-14-3 cruises, principal researcher Dr. H. Ogawa (The University of Tokyo), Dr. A. Tsuda (The University of Tokyo), Dr. M. Sato (The University of Tokyo) and other researchers for their support with onboard aerosol measurements. We are also grateful to Dr. H. Furutani and Mr. Y. Miki for sampling aerosol particles during the KH-13-7 cruise, and Mr. S. Yokoyama for analyzing the radon data during both cruises. We appreciate Dr. K. Hara (Fukuoka University), Dr. I. Hashimoto (Tokyo University of Science) and Dr. Y. Narita (Atmosphere and Ocean Research Institute, The University of Tokyo) for their helpful comments.

Open Access This article is distributed under the terms of the Creative Commons Attribution 4.0 International License (http://creativeco mmons.org/licenses/by/4.0/), which permits unrestricted use, distribution, and reproduction in any medium, provided you give appropriate credit to the original author(s) and the source, provide a link to the Creative Commons license, and indicate if changes were made.

\section{Appendix}

See Fig. 9. 
Fig. 9 TEM images of each sample. A white line is a scale bar of $5 \mu \mathrm{m}$
No. 1

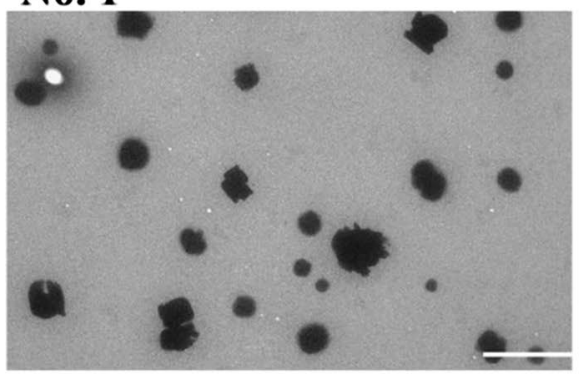

No. 3

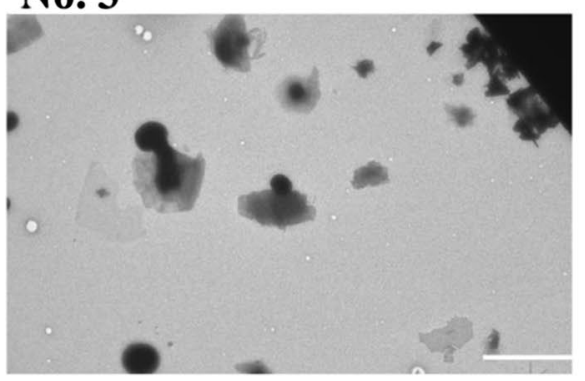

No. 5

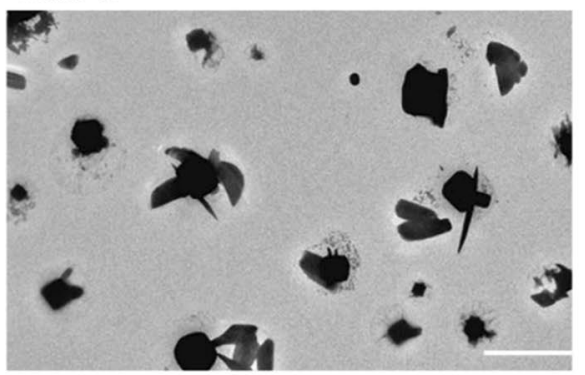

No. 7

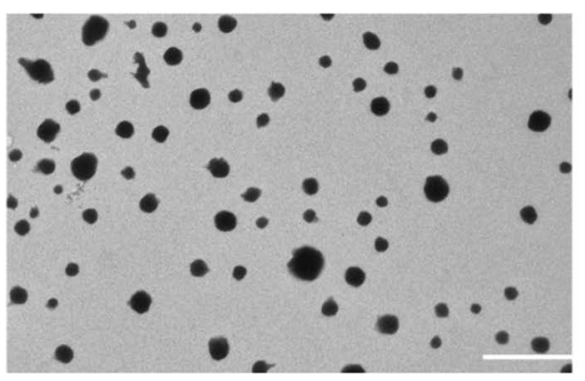

No. 2

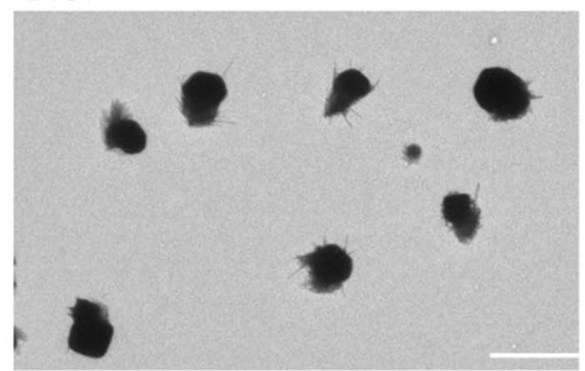

No. 4

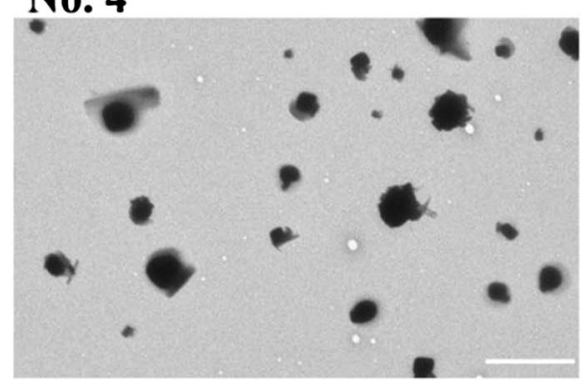

No. 6

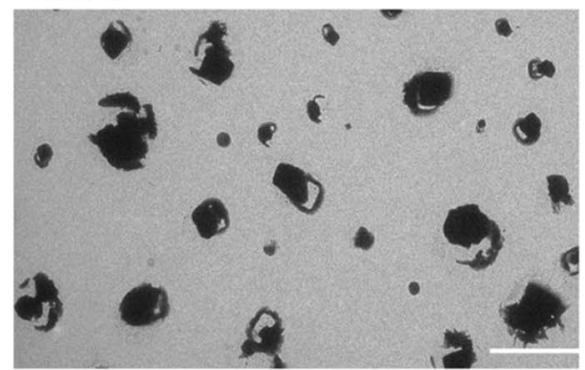

No. 8

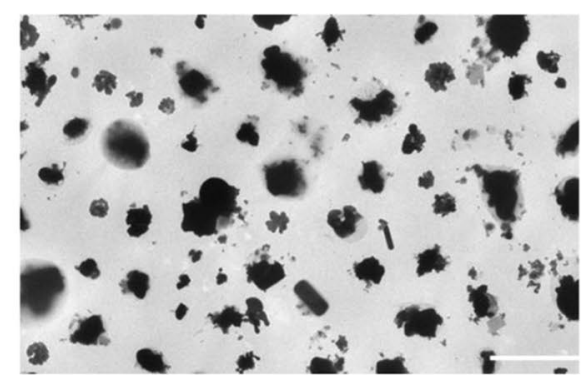

\section{References}

Adachi K, Buseck PR (2015) Changes in shape and composition of seasalt particles upon aging in an urban atmosphere. Atmos Chem 100:1-9. https://doi.org/10.1016/j.atmosenv.2014.10.036

Berresheim H, Eisele FL, Tanner DJ, Mclnnes LM, Ramsey-Bell DC, Covert DS (1993) Atmospheric sulfur chemistry and cloud condensation nuclei (CCN) concentrations over the northeastern Pacific Coast. J Geophys Res Atmos 98(D7):12701-12711. https ://doi.org/10.1029/93JD00815

Chi JW, Li WJ, Zhang DZ, Zhang JC, Lin YT, Shen XJ, Sun JY, Chen JM, Zhang XY, Zhang YM, Wang WX (2015) Sea salt aerosols as a reactive surface for inorganic and organic acidic gases in the Arctic troposphere. Atmos Chem Phys 15:11341-11353. https:// doi.org/10.5194/acp-15-11341-2015

Furutani H, Jung J, Miura K, Takami A, Kato S, Kaji Y, Uematsu M (2011) Single-particle chemical characterization and source apportionment of iron-containing atmospheric aerosols in Asian outflow. J Geophys Res 116:D18204. https://doi. org/10.1029/2011JD015867

Gong SL, Barrie LA (2003) Simulating the impact of sea salt on global nss sulphate aerosols. J Geophys Res Atmos 108(D16):4516. https ://doi.org/10.1029/2002JD003181

Hara K, Osada K, Kido M, Matsunaga K, Iwasaka Y, Hashida G, Yamanouchi T (2005) Variations of constituents of individual 
sea-salt particles at Syowa station, Antarctica. Tellus B 57(3):230246. https://doi.org/10.3402/tellusb.v57i3.16530

Hara K, Osada K, Yamanouchi T (2013) Tethered balloon-borne aerosol measurements: seasonal and vertical variations of aerosol constituents over Syowa Station, Antarctica. Atmos Chem Phys 13:9119-9139. https://doi.org/10.5194/acp-13-9119-2013

IPCC (2013) IPCC(AR5): climate change 2013: the physical science basis, summary for policymakers, contribution of working group to the fifth assesment report. IPCC, Switzerland

Kasten F (1968) Falling speed of aerosol particles. J Appl Meteorol 7(5):944-947. https://doi.org/10.1175/15200450(1968)007\%3c0944:FSOAP\%3e2.0.CO;2

Laskin A, Moffet RC, Gilles MK, Fast JD, Zaveri RA, Wang B, Nigge P, Shutthanandan J (2012) Tropospheric chemistry of internally mixed sea salt and organic particles: surprising reactivity of $\mathrm{NaCl}$ with weak organic acids. J Geophys Res 117:D15302. https://doi. org/10.1029/2012JD017743

LeGrande AN, Tsigaridis K, Bauer SE (2016) Role of atmospheric chemistry in the climate impacts of stratospheric volcanic injections. Nat Geosci 9:652-655. https://doi.org/10.1038/ngeo2771

Li W, Shao L, Shen R, Yang S, Wang Z, Tang U (2011) Internally mixed sea salt, soot, and sulfates at Macao, a coastal city in South China. J Air Waste Manag Assoc 61:1166-1173. https://doi. org/10.1080/10473289.2011.603996

Li W, Xu L, Liu X, Zhang J, Lin Y, Yao X, Gao H, Zhang D, Chen J, Wang W, Harrison RM, Zhang X, Shao L, Fu P, Nenes A, Shi Z (2017) Air pollution-aerosol interactions produce more bioavailable iron for ocean ecosystems. Sci Adv 3(3):e1601749. https:// doi.org/10.1126/sciadv.1601749

Matsui H, Mahowald NM, Moteki N, Hamilton DS, Ohata S, Yoshida A, Koike M, Scanza RA, Flanner MG (2018) Anthropogenic combustion iron as a complex climate forcer. Nat Commun 9(1):1593. https://doi.org/10.1038/s41467-018-03997-0

Miura K (2000) Physical and chemical properties of aerosols in the marine boundary layer. Earozoru Kenkyu 15(4):327-334. https ://doi.org/10.11203/jar.15.327 (in Japanese)

Miura K, Kumakura T, Sekikawa T (1991) The effect of continental air mass on the modification of individual sea-salt particles collected over the coast and the open sea. J Meteorol Soc Jpn Ser II 69(4):429-438. https://doi.org/10.2151/jmsj1965.69.4_429

Mouri H, Okada K (1993) Shattering and modification of sea-salt particles in the marine atmosphere. Geophys Res Lett 20(1):49-52. https://doi.org/10.1029/92GL03004

Mouri H, Okada K, Takahashi S (1995) Giant sulfur-dominant particles in remote marine boundary layer. Geophys Res Lett 22(5):595598. https://doi.org/10.1029/94GL03394

Mouri H, Nagao I, Okada K, Koga S, Tanaka H (1996) Elemental composition of individual aerosol particles collected from the coastal marine boundary layer. J Meteorol Soc Jpn Ser II 74(5):585-591. https://doi.org/10.2151/jmsj1965.74.5_585

Mouri H, Nagao I, Okada K, Koga S, Tanaka H (1999) Individual-particle analyses of coastal Antarctic aerosols. Tellus B 51(3):603611. https://doi.org/10.3402/tellusb.v51i3.1644

Ooki A, Miura K, Uematsu M (2003) The increase of biogenic sulfate aerosol and particle number in marine atmosphere over the Northwestern North Pacific. J Oceanogr 59(6):799-807. https:// doi.org/10.1023/B:JOCE.0000009571.81193.5d

Rolph G, Stein A, Stunder B (2017) Real-time environmental applications and display system: READY. Environ Model Softw 95:210 228. https://doi.org/10.1016/j.envsoft.2017.06.025

Seinfeld JH, Pandis SN (2016) Atmospheric chemistry and physics: from air pollution to climate change. John Wiley \& Sons, Hoboken

Stein AF, Draxler RR, Rolph GD, Stunder BJB, Cohen MD, Ngan F (2015) NOAA's HYSPLIT atmospheric transport and dispersion modeling system. Bull Am Meteorol Soc 96(12):2059-2077. https ://doi.org/10.1175/BAMS-D-14-00110.1

Tomimatsu M, Miura K, Ueda S, Furutani H, Uematsu M (2012) Properties of individual aerosol particles collected over the East Philippines Ocean. Proc Soc Atmos Electr Jpn 6(1):170-171 (in Japanese)

U.S. Standard Atmosphere (1976) U.S. Government Printing Office, Washington, D.C

Volcano Discovery. http://www.volcanodiscovery.com. Accessed 1 Nov 2017 